\title{
Effects of host stage and number of feeding larvae on parasitism success and fitness in the coleopteran parasitoid, Dastarcus longulus Sharp (Coleoptera: Bothrideridae)
}

\author{
Tadahisa URANo* \\ Forestry and Forest Products Research Institute; Tsukuba, Ibaraki 305-8687, Japan
}

(Received 2 July 2009; Accepted 11 November 2009)

\begin{abstract}
Fitness elements (number and weight of emerging adults) and the success of parasitism (host mortality) in Dastarcus longulus were compared among three host stages (Monochamus alternatus larvae, pupae and adults). Different numbers of first-instar larvae were released onto single host individuals to determine the optimal host quality and rearing conditions needed to obtain large numbers of high-fitness individuals and to maximize the rearing efficiency of the parasitoid. Host mortality after the release of a single parasitoid larva was $88 \%$ on pupal hosts but $<50 \%$ on larval and adult hosts. The numbers and weights of emerging adults per host were highest on pupal hosts. The estimated number of ovarioles in emerging adults was also the highest on pupal hosts. Pupae of M. alternatus thus provided the best host quality for rearing $D$. longulus. High host mortality was caused mainly by pupal immobility. A high feeding rate was associated with high parasitoid reproductive potential on pupal hosts. Although the release of 10 larvae onto a single pupal host resulted in the highest overall fitness of the rearing population of D. longulus, the release of two larvae onto each pupal host was the optimal procedure for maximizing the weight of individuals.
\end{abstract}

Key words: Dastarcus longulus; coleopteran parasitoid; fitness; Monochamus alternatus

\section{INTRODUCTION}

Dastarcus longulus Sharp is a parasitoid of cerambycid beetles. Adult females deposit egg clusters on gallery walls bored into the stems of trees by host larvae (Gao and Qin, 1992). Hatched larvae seek out and paralyze their hosts. Larvae that successfully parasitize hosts feed externally on the hosts and grow rapidly. Mature larvae spin cocoons and pupate, emerging in August and September (Urano et al., 2004), and then overwintering as adults in central Japan. D. longulus parasitizes the larvae, pupae, and adults of Monochamus alternatus Hope (Coleoptera: Cerambycidae), the primary vector of the pine wood nematode, Bursaphelenchus xylophilus (Steiner and Buhrer) Nickle in Japan. The release of $D$. longulus has a detrimental effect on $M$. alternatus survival; the mortality of M. alternatus was about $57-76 \%$ in trees treated with $D$. longulus, which was significantly higher than in control, untreated trees (5-27\%) (Urano,
2006). Artificial diets have been developed for larvae and adults of D. longulus (Ogura et al., 1999), which are reared for the biological control of M. alternatus and other cerambycid beetles.

D. longulus is reared in the laboratory using either an artificial diet or live M. alternatus larvae or pupae. Although an artificial diet allows the parasitoids to be reared in any season, live insects, such as the full-grown larvae of Galleria mellonella (Linnaeus), are necessary for the development of first-instar parasitoid larvae. Thus, the latter method is more labor-saving if a number of dead pine $\operatorname{logs}$ bored by M. alternatus are available.

In coleopteran parasitoids, female beetles lay eggs where there is general evidence of host activity, and the precise location and selection of hosts is performed by mobile first-instar larvae (Eggleton and Belshaw, 1993; Godfray, 1994; Fournet et al., 2001). In contrast to most hymenopteran parasitoids, coleopteran parasitoids are considered to have only a minimal influence on parasitism suc-

*E-mail: urano@ffpri.affrc.go.jp

DOI: 10.1303/aez.2010.215 
cess and the fitness of their progeny, because they do not directly select and evaluate host suitability (Godfray, 1994). Although host-seeking first-instar larvae are mobile, the time available and the area that can be searched by a larva are considerably less than for an adult female. Thus, the number of potential hosts encountered is reduced and, in most cases, once a choice of host is made, it is final. It seems likely that the reduced mobility and low encounter rate of parasitoid larvae reflects a reduction in the resources used to evaluate the host (Brodeur and Boivin, 2004).

D. longulus adults live for $2-3$ years in the laboratory, and a female can produce $>2,000$ eggs per year (Inoue, 1993; Ishii, 2004). These characteristics compensate for the lack of opportunities to encounter hosts in the field. In addition, first-instar larvae rarely avoid hosts already parasitized by other individuals (T. Urano, unpublished data). Regarding mass rearing for biological control, the long life and high fecundity of D. longulus enables a large number of eggs to be obtained over a long period. Moreover, hosts and artificial diets can easily be substituted and evaluated. Thus, we can select host individuals that increase parasitoid fitness the most, to increase the efficiency of mass rearing.

A positive correlation between body size or weight and fecundity has been shown for many parasitoids (Jervis and Copland, 1996). In several parasitoid wasps, the fitness elements (developmental rate, body size or egg load) of the progeny increased with progressive host stages at the time of parasitism (e.g., Nechols and Kikuchi, 1985; Bell et al., 2003; He et al., 2005). As D. longulus parasitizes larvae, pupae, and adults of M. alternatus, the fitness of the progeny is expected to differ with the host stage. More than one individual of $D$. longulus could exploit a single M. alternatus host, because between one and nine adults were seen to emerge from one host pupal chamber in the field (Ishii, 2003). Thus, the number of parasitoid larvae released onto a host may also affect the fitness of the parasitoid progeny.

The aim of this study was to determine the host quality and rearing conditions required to obtain large numbers of high-fitness individuals to maximize the rearing efficiency of $D$. longulus. The fitness elements (number and weight of emerging adults) and success of parasitism (host mortality) of D. longulus were compared among the three host stages (larvae, pupae, and adults).

\section{MATERIALS AND METHODS}

D. longulus adults were laboratory-reared offspring of adults collected from dead Pinus densiflora Sieb. et Zucc. (Pinaceae) trees at Wake-cho in Okayama Prefecture $\left(34^{\circ} 49^{\prime} \mathrm{N}, 134^{\circ} 08^{\prime} \mathrm{E}\right)$ in May 1999. Experiments were conducted at Kansai Research Center, Forestry and Forest Products Research Institute, Kyoto. Adults were reared in plastic Petri dishes ( $95 \mathrm{~mm}$ in diameter, $23 \mathrm{~mm}$ high) lined with filter paper and containing a block of pine wood $(15 \times 15 \times 50 \mathrm{~mm})$ with a hole drilled in it ( $9 \mathrm{~mm}$ in diameter, $40 \mathrm{~mm}$ deep), as an oviposition site. A piece of artificial diet (1-2 mg/adult) was provided once a week. The main ingredient of the artificial diet was silkworm pupa powder (Marukyu Corp., Japan; Ogura et al., 1999). An absorbent cotton ball moistened with tap water was placed in a small plastic container $(20 \mathrm{~mm}$ in diameter, $12 \mathrm{~mm}$ high). The adults were maintained at $28^{\circ} \mathrm{C}$ under a 16 -h light (L) : 8-h dark (D) photoperiod. Wood blocks containing the eggs were transferred to new Petri dishes and maintained at $25^{\circ} \mathrm{C}$ under a $16 \mathrm{~L} 8 \mathrm{D}$ photoperiod until hatching.

First-instar larvae of $D$. longulus were released on full-grown larvae, pupae, or adults of $M$. alternatus that had been collected from dead $P$. densiflora at the Kansai Research Center. Adults, which were collected as pupae, were emerged individually in plastic vials $(25 \mathrm{~mm}$ in diameter, $60 \mathrm{~mm}$ long) and used in experiments within 1 week of emergence.

One host individual was weighed on a microbalance and put in a styrene case $(60 \times 43 \times 19 \mathrm{~mm})$ lined with filter paper. First-instar larvae of $D$. longulus were released into the case using a moistened writing brush. One, two, five or 10 parasitoid larvae were released onto one M. alternatus individual of each developmental stage, and each experiment was repeated 40 times. The cases were maintained at $25^{\circ} \mathrm{C}$ under a $16 \mathrm{~L} 8 \mathrm{D}$ photoperiod and each host was checked daily for signs of paralysis or of being eaten by D. longulus larvae. Host individuals that were still active 1 week after the release of parasitoids were considered to be unparasitized. When the hosts were completely eaten or the parasitoid larvae fully developed, the number of fully-grown larvae on each host was counted. The 
larvae were individually transferred into new styrene cases lined with tissue paper for spinning cocoons, and were maintained at $25^{\circ} \mathrm{C}$ under a 16L8D photoperiod. Emerged adults were counted and individually weighed on a microbalance. Togashi and Itabashi (2005) demonstrated that the body length of $D$. longulus was positively correlated with other body measurements, including fresh weight and the number of ovarioles. Thus, the number of ovarioles of emerged adults was estimated based on their regression equation (Togashi and Itabashi, 2005).

Statistical analysis. Differences in host mortality among developmental stages were analyzed using the $\chi^{2}$ test. The feeding period, the number and weight of emerged adults, and the number of ovarioles were analyzed using a generalized linear model (GLM). The feeding period, number of emerged adults, and the weight of individual adults were analyzed after Box-Cox transformation. The developmental stage of the host, the number of $D$. longulus first-instar larvae released on a host, and their interaction were included as sources of variables. Regression analyses were performed to determine the relationships between host weight and the number and weight of emerged D. longulus. All analyses were carried out using MINITAB release 14.

\section{RESULTS}

\section{Feeding behavior of $\boldsymbol{D}$. longulus larvae}

When a first-instar larva reached a host, they bit it, inducing paralysis, and then started to feed on it. If the host was a larva, most first-instar parasitoid larvae entered between the segments of the host and parasitized it. In the case of host pupae, the first-instar larvae generally bit at the root of the host's legs or wings. On a host adult, the first-instar larvae were only able to parasitize the dorsal thorax or abdomen under the elytra and hind wings, because the exoskeleton was sclerotized on other parts of the adult's body. The host's cuticle surrounding the wounds made by the parasitizing larvae darkened, as seen in Brachinus spp. (Saska and Honek, 2004). The hosts were completely immobilized while first-instar larvae fed on them. Feeding second or third instar larvae often penetrated the host body. Cannibalism was also observed during this phase if the number of parasitoid larvae was high relative to host size. A number of hosts decomposed during the feeding process, and larval hosts were more likely to decompose than pupal hosts. If the host decomposed when parasitoid larvae were at the second or third instar stage, most parasitoid larvae were still able to feed on the host and pupate; however, most first-instar larvae feeding on decomposed hosts died.

\section{Feeding period of $D$. longulus larvae}

The feeding periods (days from release to the end of host feeding) of $D$. longulus larvae released at different densities and on different host stages are shown in Fig. 1. As a result of GLM analysis, the main effects of both host stage and the number of parasitoid larvae released on a host, and their interaction were all significant $(p<0.001)$. D. longulus larvae took longer to develop on larval hosts than on pupal hosts. The standard deviation for feeding time on pupal hosts was smaller than for feeding times on larvae or adults for all densities of released larvae. The feeding period decreased with the number of released larvae on both larval and pupal hosts. The developmental rates of feeding larvae (reciprocal numbers of feeding period in each number of released larvae) on pupal hosts were 1.6-1.7 times faster than on larval hosts.

\section{Host mortality}

The number of dead hosts following parasitism

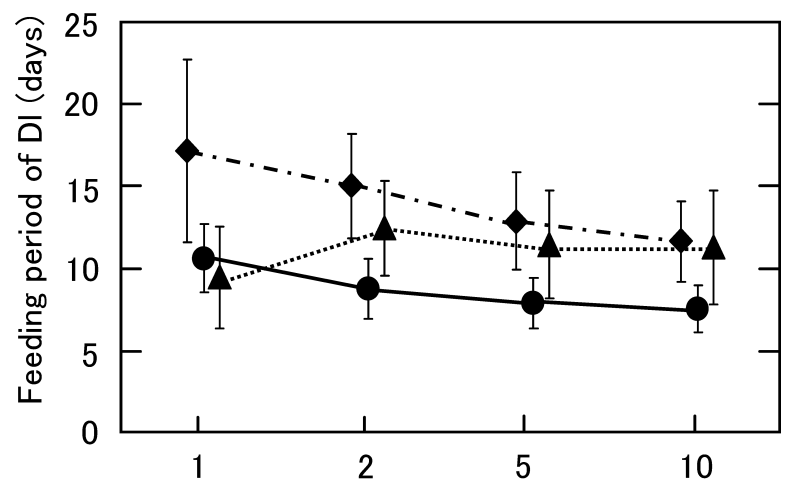

No. of DI first instar larvae on a single host

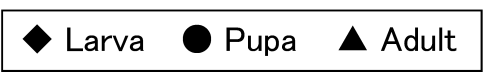

Fig. 1. Feeding period (days from release to the end of host feeding, mean $\pm \mathrm{SD}$ ) of $D$. longulus (D1) larvae released at different densities onto $M$. alternatus individuals of different stages. As a result of GLM analysis, the main effects of both host stage and the number of parasitoid larvae released on a host, and their interaction, were all significant $(p<0.001)$. 
Table 1. Number (percentage) of dead hosts due to $D$. longulus parasitism based on $40 \mathrm{M}$. alternatus individuals of each density of $D$. longulus larvae released onto M. alternatus individuals of different stages

\begin{tabular}{|c|c|c|c|c|}
\hline \multirow{2}{*}{ Host stage } & \multicolumn{4}{|c|}{$\begin{array}{l}\text { No. of } D \text {. longulus first-instar larvae } \\
\text { on a single host }\end{array}$} \\
\hline & 1 & 2 & 5 & 10 \\
\hline Larva & $13(33)^{\mathrm{b} *}$ & $28(70)^{b}$ & $32(80)^{\mathrm{b}}$ & $36(90)^{\mathrm{ab}}$ \\
\hline Pupa & $35(88)^{\mathrm{a}}$ & $39(98)^{\mathrm{a}}$ & $40(100)^{\mathrm{a}}$ & $40(100)^{\mathrm{a}}$ \\
\hline Adult & $19(48)^{\mathrm{b}}$ & $29(70)^{b}$ & $29(70)^{b}$ & $34(85)^{b}$ \\
\hline
\end{tabular}

* Values followed by a different letter are significantly different ( $p<0.05 ; \chi^{2}$ test).

of $40 \mathrm{M}$. alternatus individuals of different developmental stages by different numbers of $D$. longulus individuals is shown in Table 1. The mortality of pupal hosts was high (88\%), even when only a single parasitoid larva was released, and all pupae were killed after the release of five or 10 parasitoid larvae. The mortality of larval and adult hosts, however, was $<50 \%$ following the release of a single parasitoid larva, but increased to $70-90 \%$ when multiple larvae were released. The mortality of pupal hosts was significantly higher than that of adult hosts at all densities of released larvae, and higher than that of larval hosts, except after the release of 10 larvae $\left(\chi^{2}\right.$ test, $\left.p<0.05\right)$.

\section{Emergence rate}

Mortality at two different stages (from first-instar to the end of host feeding, and from the end of host feeding to emergence), and the emergence rate of D. longulus on each host stage is shown in Fig. 2. The emergence rate was highest on pupal hosts and lowest on adult hosts. On larval hosts, $64-78 \%$ of released larvae died before emergence, and mortality was slightly higher after single release than after multiple releases (Fig. 2a). Conversely, the emergence rate on pupal hosts was highest after a single release, and decreased with increasing numbers of released larvae (Fig. 2b). On adult hosts, $83-92 \%$ of released larvae died during first-instar and host-feeding stages (Fig. 2c).

Although mortality during the stage after fullygrown larvae was generally low, it increased in 10larva release experiments with larval and pupal hosts. When 10 larvae were released on a larval host, the emergence rates of parasitoids $<30 \mathrm{mg}$

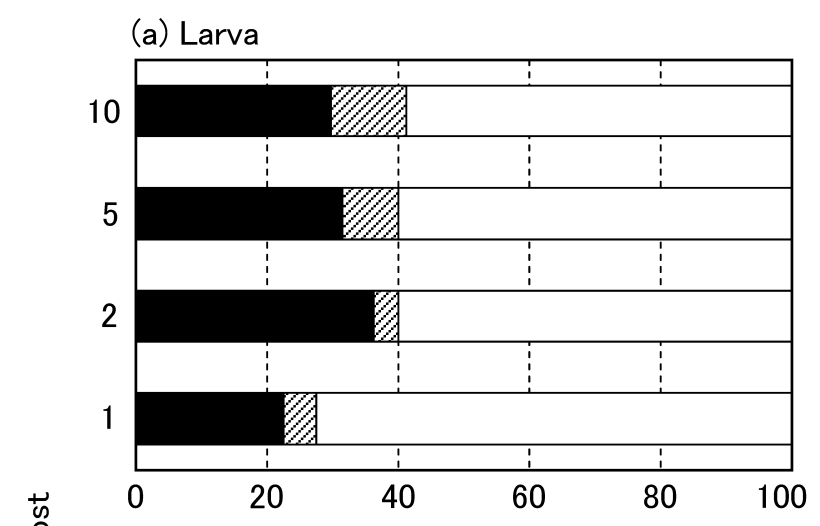

(b) Pupa

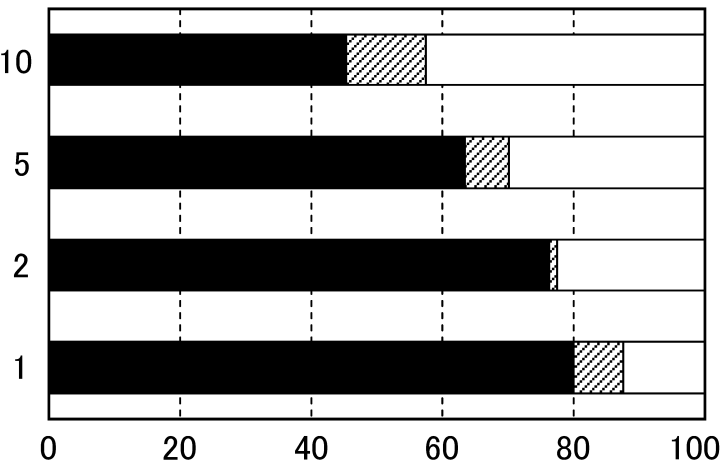

(c) Adult

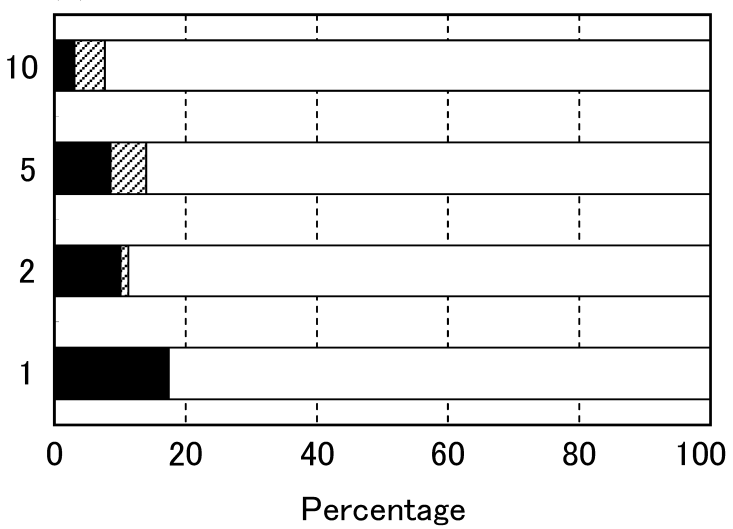

Emerged

Dead full-grown larvae and pupae

Dead 1st instar and host-feeding larvae

Fig. 2. Mortality during each of the two stages (from first instar to host-feeding larvae, and from fully grown larvae to emergence) and the emergence rate of $D$. longulus (D1) for each density of $D$. longulus larvae released onto M. alternatus individuals of different stages.

fresh weight and $<20 \mathrm{mg}$ fresh weight at the end of host feeding were $41 \%$ and $19 \%$, respectively. On pupal hosts, the equivalent emergence rates were 
$42 \%$ and $3 \%$, respectively.

\section{Number of emerging adults per host}

Figure 3 shows the number of emerging adults of D. longulus per host for each treatment. As a result of GLM analysis, the main effects of both host stage and the number of parasitoid larvae released on a host, and their interaction, were all significant $(p<0.001)$. The number of adults was highest on pupal hosts, and increased with the number of released larvae on larval and pupal hosts. The number of emerging parasitoids on adult hosts was $<1$ individual at all densities of released larvae.

\section{Weight of emerging adults}

Figure 4a shows the mean weight of emerging $D$. longulus adults after each treatment. As a result of GLM analysis, the main effects of both host stage and the number of parasitoid larvae released on a host $(p<0.001)$, and their interaction, $(p=0.011)$ were all significant. Although adult weight generally decreased with increasing numbers of released larvae on all host stages, adult weight was largest when two larvae were released on pupal hosts. The mean weight on pupal hosts was larger than the other two host stages irrespective of the number of released larvae.

The total mass of emerging D. longulus adults per host after each treatment is shown in Fig. $4 \mathrm{~b}$.

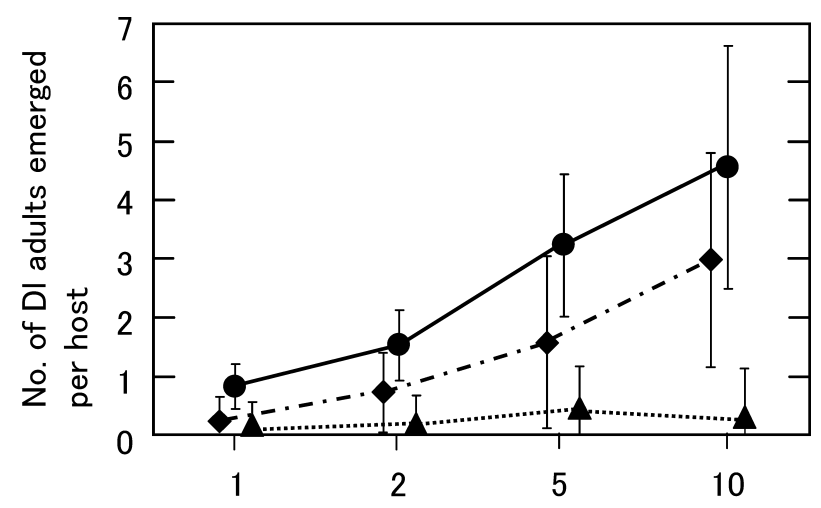

No. of DI first instar larvae on a single host

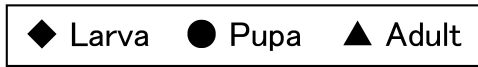

Fig. 3. Number of emerging adults (mean \pm SD) of $D$. longulus (D1) per host for each density of $D$. longulus larvae released onto $M$. alternatus individuals of different stages. As a result of GLM analysis, the main effects of both host stage and the number of parasitoid larvae released on a host, and their interaction, were all significant $(p<0.001)$.
As a result of GLM analysis, the main effects of both host stage and the number of parasitoid larvae released on a host $(p<0.001)$, and the interaction of them $(p=0.001)$, were all significant. The adult mass on larval and pupal hosts increased with the number of released larvae, but remained almost the same on adult hosts, irrespective of the number of released larvae. The mass on pupal hosts increased steeply and was greater than on larval or adult hosts.

\section{Number of ovarioles}

The mean number of ovarioles of emerging $D$. longulus adults (estimated using Togashi and Itabashi's 2005 regression equation) after each
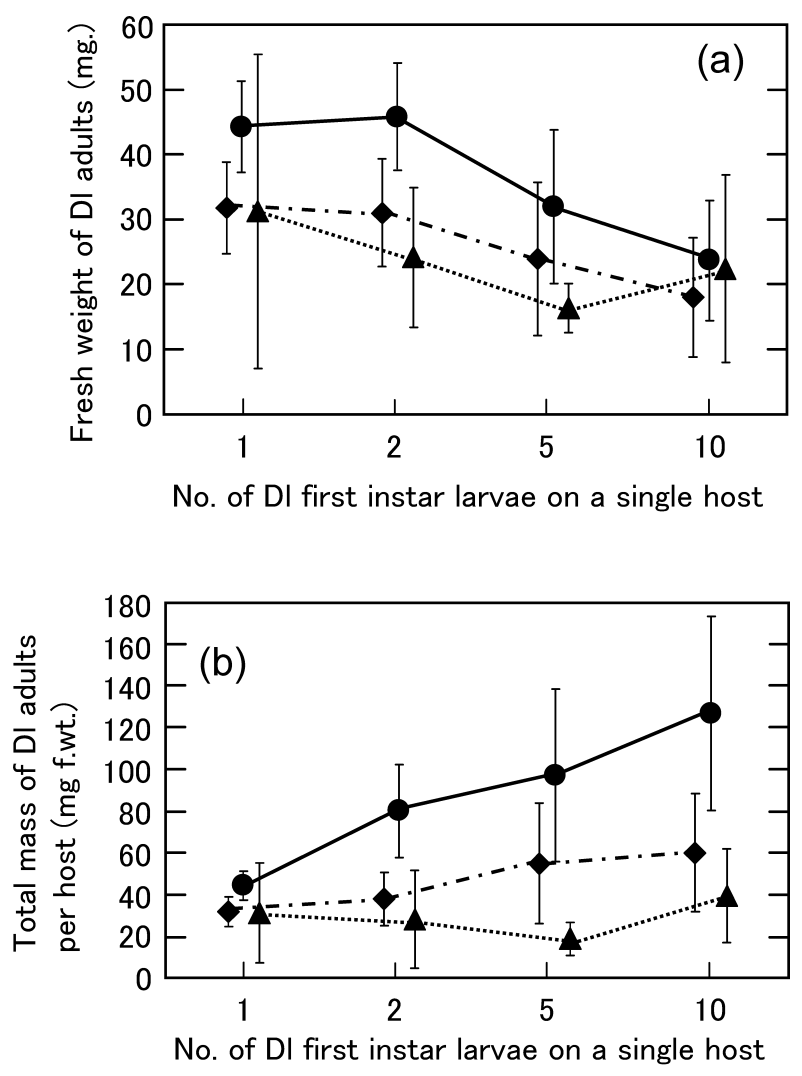

$$
\checkmark \text { Larva Pupa Adult }
$$

Fig. 4. (a) Weight of emerging D. longulus (D1) adults and (b) Total mass of emerging $D$. longulus adults per host (mg fresh weight, mean $\pm \mathrm{SD}$ ) for each density of $D$. longulus larvae released onto $M$. alternatus individuals of different stages. As a result of GLM analysis, the main effects of both host stage and the number of parasitoid larvae released on a host $(p<0.001$ for both (a) and (b)), and their interaction ( $p=0.011$ and 0.001 for (a) and (b), respectively), were all significant. 
treatment is shown in Fig. 5a. As a result of GLM analysis, the main effects of host stage and the number of parasitoid larvae released on a host were both significant $(p<0.001)$, but their interaction was not significant $(p=0.075)$. The mean number of ovarioles was largest on pupal hosts and decreased with the number of released parasitoid larvae. The number of ovarioles on each host stage followed the same pattern as changes in adult weight (Fig. 4a), because there is a linear relationship between adult weight and the number of ovarioles (Togashi and Itabashi, 2005).

The total number of ovarioles in D. longulus adults per host after each treatment is shown in Fig.

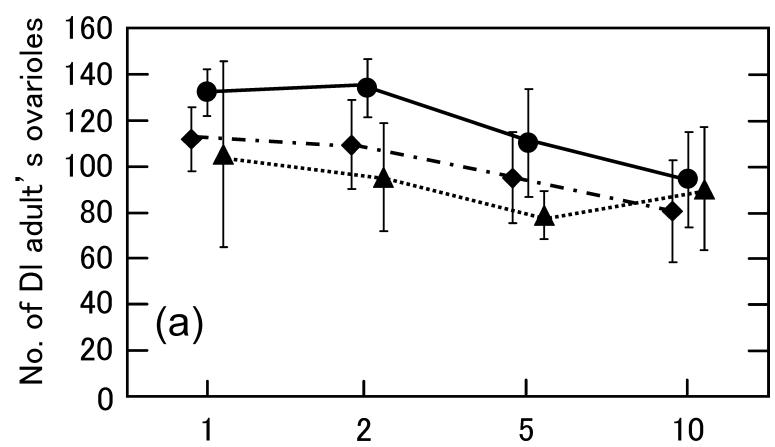

No. of DI first instar larvae on a single host

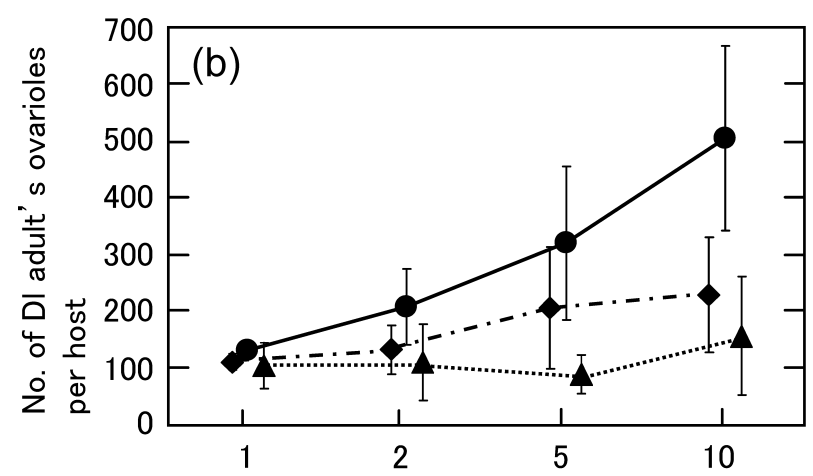

No. of DI first instar larvae on a single host

\section{Larva Pupa A Adult}

Fig. 5. (a) Number of ovarioles in emerging D. longulus (D1) adults and (b) total number of ovarioles in D. longulus adults per host (mean \pm SD, estimated using Togashi and Itabashi (2005)'s regression equation) for each density of $D$. longulus larvae released onto $M$. alternatus individuals of different stages. As a result of GLM analysis, the main effects of host stage and the number of parasitoid larvae released on a host were both significant $(p<0.001)$ for both (a) and (b), whereas their interaction was not significant $(p=0.075)$ for (a) but was significant $(p<0.001)$ for (b). 5b. As a result of GLM analysis, the main effects of both host stage and the number of parasitoid larvae released on a host, and their interaction, were all significant $(p<0.001)$. The total number of ovarioles increased most steeply with the number of released larvae on pupal hosts, and was higher than on larval or adult hosts, as seen for total mass (Fig. 4b).

\section{Relationships between host weight and the num- ber and mass of emerging adults}

The relationships between host weight and the number of $D$. longulus adults emerging after the release of 10 larvae onto larval or pupal hosts are shown in Fig. 6. The correlation was only significant for release on pupal hosts, where the number of emerging adults increased with host weight (Fig. $6 b)$.

The relationships between host weight and the total mass of emerging $D$. longulus adults per host

(a) $10 \mathrm{DI}$ larvae on a single Ma larva

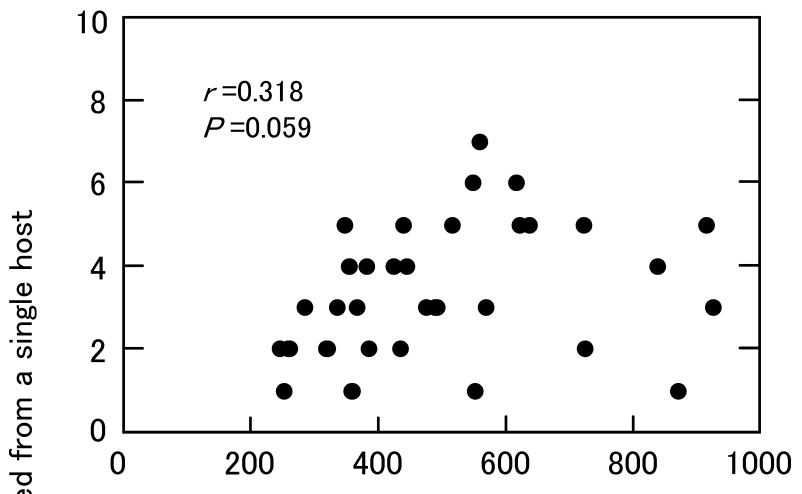

(b) $10 \mathrm{DI}$ larvae on a single Ma pupa

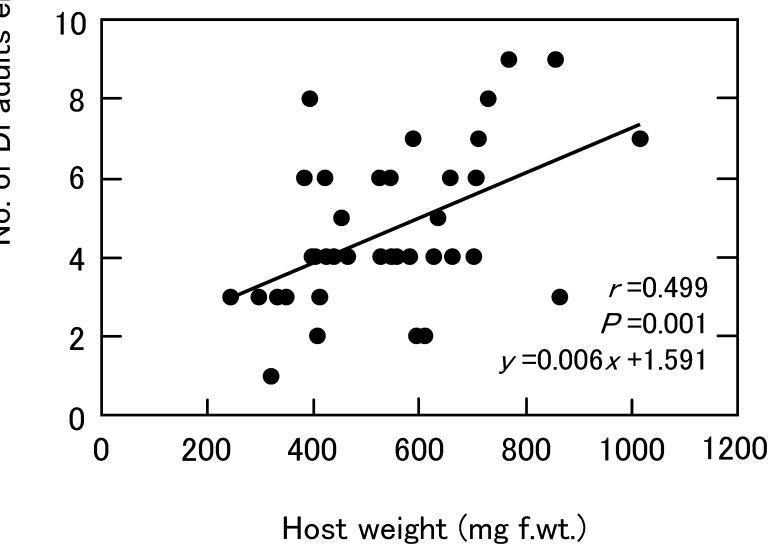

Fig. 6. Relationships between host fresh weight $(\mathrm{mg})$ and number of D. longulus (D1) adults after the release of 10 larvae onto larval and pupal M. alternatus (Ma). 
(a) 10 DI larvae on a single Ma larva

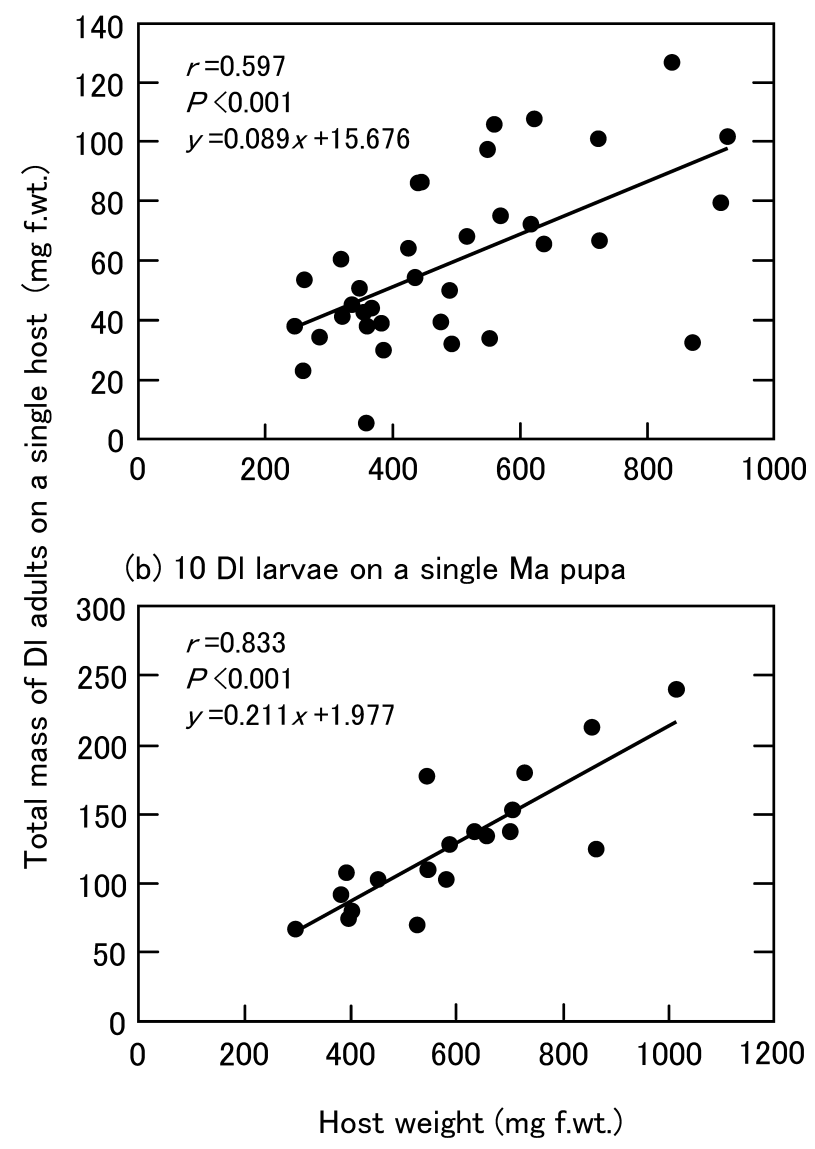

Fig. 7. Relationships between host weight and total mass (mg fresh weight) of D. longulus (D1) emerging per host after release of 10 larvae onto larval and pupal M. alternatus (Ma).

after the release of 10 larvae onto larval or pupal hosts are shown in Fig. 7. Host weight was positively correlated with adult mass in both cases (Fig. $7 \mathrm{a}, \mathrm{b})$.

\section{DISCUSSION}

The results of our experiments demonstrate that the pupal stage of $M$. alternatus provides the best quality host for D. longulus. Host mortality and the emergence rate of $D$. longulus were highest on pupal hosts. The mortality of pupal hosts after the release of a single parasitoid was always high, whereas it was lower for larval and adult hosts. As M. alternatus larvae and adults are more active than pupae, first-instar larvae of D. longulus tend to fall off the host body more easily, and so fail to paralyze and feed on the host. Thus, first-instar larvae entered between the segments of larval hosts to avoid falling off. In the case of adult hosts, first-instar larvae need to reach the dorsal thorax or abdomen under the elytra and hind wings to successfully parasitize them, because the integument elsewhere is too hard for first instars to bite.

The results of this study indicate that the release of D. longulus into the field for the biological control of $M$. alternatus should be performed during the pupal period of the host to maximize the parasitism rate. Pupation of M. alternatus is observed from mid-May to mid-July in the field, and the pupal period lasts for 17-19 days in Ibaraki Prefecture, central Japan (Kishi, 1995). The emergence of adults continues for about 2 months, thus $M$. alternatus pupae always mix with other stages, i.e., larvae or adults, in the field. D. longulus should be released before the emergence of $M$. alternatus adults, because the parasitism rate of adults is low, and adults cannot be parasitized once they have left the trees.

It was possible to obtain many adult parasitoids with high reproductive potential from pupal hosts, because the number of emerging adults per host, the mass of the emerging adults, and the number of ovarioles were all highest on pupal hosts. This was mainly due to the faster developmental rate on pupal hosts, relative to larval or adult hosts. Parasitized hosts easily decomposed during the feeding process. One possible reason for this is that $D$. longulus larvae excrete feces while feeding on their hosts, unlike hymenopteran parasitoids. Host decomposition during feeding can cause the high mortality of parasitoid larvae and a reduction in the size of emerging adults. Thus, it is important for $D$. longulus larvae to feed quickly and so avoid host decomposition.

The correlation between host weight and the mass of emerging $D$. longulus was significant for both larval and pupal hosts, but the mass of $D$. longulus was more variable on larval hosts (Fig. 7). This indicates that the host mass was converted into a parasitoid mass at an almost constant rate for pupal, but not larval, hosts. Moreover, the number of emerging $D$. longulus increased with increasing numbers of released larvae in the case of larval hosts (Fig. 3), but total mass reached a plateau (Fig. 4b). On pupal hosts, however, total mass also increased steeply with increasing numbers of released larvae. This suggests that the loss of nutrition caused by host deterioration was greater on 
larval than pupal hosts. The larger part of released larvae could emerge from the large pupal host because the relationship between host weight and the number of $D$. longulus adults was significant (Fig. $6 b)$.

On adult hosts, the number and mass of emerging $D$. longulus barely increased with increased larval density. The nutrition derived from an adult host is small, because relatively more of the individual, such as the exoskeleton, is inedible, compared with larvae and pupae. As parasitism success (measured as host mortality) was almost the same between adult and larval hosts (Table 1), M. alternatus adults are not so difficult to parasitize for $D$. longulus relative to larvae, and a number of adults were parasitized in a field release experiment (Urano, 2006); however, the value of adult hosts as a resource for $D$. longulus offspring is obviously low.

The total adult mass and the number of ovarioles per host, which both increased with increasing larval density, could be increased by releasing more than 10 larvae; however, the mean number of emerging adults per released first-instar larva tended to decline $(0.825,0.763,0.645$, and 0.455 , for one, two, five, and 10 larvae released on pupal hosts, respectively). Competition among parasitoid larvae for host resources becomes severe and the frequency of cannibalism increases as larval density increases. The emergence rate also fell with a decreased parasitoid larval size. Even if adults emerge, their longevity and fecundity could be reduced. Thus, higher fitness levels are unlikely to be achieved by increasing the number of larvae released per host.

Although the release of 10 larvae onto a single pupal host resulted in the highest overall fitness of the rearing population of $D$. longulus, the fitness (adult weight and number of ovarioles) of each individual adult was small. In addition, Togashi and Itabashi (2005) suggested that a rearing procedure that allowed newly hatched larvae to develop into large female adults might be crucial for successful biological control. The release of two D. longulus individuals onto each pupal host was the optimal procedure for maximizing the weight (=fitness) of individuals (Fig. 4a). Wide variation in the number of ovarioles per female suggests that individual differences in daily and lifetime fecundity exist among females, depending on body length (To- gashi and Itabashi, 2005). The effects of adult size on longevity and lifetime fecundity need to be further investigated to determine the optimal number of released larvae per host.

\section{ACKNOWLEDGMENTS}

I would like to thank Dr. N. Hijii, Nagoya University, for critical reading of the manuscript. Thanks are also extended to Dr. N. Ogura, Meiji University, and T. Makimoto, Okayama Prefectural Forest Experiment Station, for their valuable support with the collection and rearing of D. longulus.

\section{REFERENCES}

Bell, H. A., G. C. Marris, F. Smethurst and J. P. Edwards (2003) The effect of host stage and temperature on selected developmental parameters of the solitary endoparasitoid Meteorus gyrator (Thun.) (Hym., Braconidae). J. Appl. Entomol. 127: 332-339.

Brodeur, J. and G. Boivin (2004) Functional ecology of immature parasitoids. Annu. Rev. Entomol. 49: 27-49.

Eggleton, P. and R. Belshaw (1993) Comparisons of dipteran, hymenopteran and coleopteran parasitoids: provisional phylogenetic explanations. Biol. J. Linn. Soc. 48: 213-226.

Fournet, S., D. Poinsot, E. Brunel, J. P. Nenon and A. M. Cortesero (2001) Do female coleopteran parasitoids enhance their reproductive success by selecting high-quality oviposition sites? J. Anim. Ecol. 70: 1046-1052.

Gao, R. and X. Qin (1992) Colydiidae. In Forest Insects of China (G. Xiao, ed.). China Forestry Publishing House, Beijing, pp. 445-446 (in Chinese).

Godfray, H. C. J. (1994) Parasitoids. Princeton University Press, Chichester. 473 pp.

He, X. Z., Q. Wang and D. A. J. Teulon (2005) Host stage preference and reproductive fitness of Aphidius eadyi (Hymenoptera: Aphidiidae) on Acyrthosiphon pisum (Hemiptera: Aphididae). New Zeal. J. Agr. Res. 48: 157-163.

Inoue, E. (1993) Dastarcus longulus, a natural enemy of the Japanese pine sawyer. Forest Pests 42: 171-175 (in Japanese).

Ishii, S. (2003) Comprehensive studies on preservation of pine forest: Utilization of Dastarcus helophoroides Fairmaire ( $=D$. longulus Sharp) as natural enemy of Monochamus alternatus Hope. Bull. Okayama Pref. For. Exp. Sta. 19: 17-33 (in Japanese).

Ishii, S. (2004) Oviposition and development of Dastarcus helophoroides (Fairmaire) ( $=D$. longulus Sharp) in the laboratory. Appl. For. Sci. 13: 49-53 (in Japanese with English summary).

Jervis, M. A. and M. J. W. Copland (1996) The life cycle. In Insect Natural Enemies: Practical Approaches to Their Study and Evaluation (M. A. Jervis and N. Kidd, eds.). Chapman \& Hall, London, pp. 63-160.

Kishi, Y. (1995) The Pine Wood Nematode and the Japanese Pine Sawyer. Thomas Company Ltd., Tokyo. 302 pp.

Nechols, J. R. and R. S. Kikuchi (1985) Host selection of the spherical mealybug (Homoptera: Pseudococcidae) by 
Anagyrus indicus (Hymenoptera: Encyrtidae): Influence of host stage on parasitoid oviposition, development, sex ratio, and survival. Environ. Entomol. 14: 32-37.

Ogura, N., K. Tabata and W. Wang (1999) Rearing of the colydiid beetle predator, Dastarcus helophoroides, on artificial diet. BioControl 44: 291-299.

Saska, P. and A. Honek (2004) Development of the beetle parasitoids, Brachinus explodens and B. crepitans (Col.: Carabidae). J. Zool. 262: 29-36.

Togashi, K. and M. Itabashi (2005) Maternal size dependency of ovariole number in Dastarcus helophoroides
(Coleoptera: Colydiidae). J. For. Res. 10: 373-376.

Urano, T. (2006) Experimental release of adult Dastarcus helophoroides (Coleoptera: Bothrideridae) in a pine stand damaged by pine wilt disease: Effects on Monochamus alternatus (Coleoptera: Cerambycidae). Bull. For. Forest Prod. Res. Inst. 5: 257-263.

Urano, T., M. Inoue, S. Ishii, Y. Ando, S. Shiomi, S. Jikumaru, S. Fukui, H. Sugimoto, M. Takemoto and T. Inada (2004) Emergence pattern of Dastarcus helophoroides in the Kansai region. Trans. Mtg. Jpn. For. Soc. 115: 245 (in Japanese). 